\title{
AN ACCOUNT OF A CASE
}

IN WHICH A

\section{SIXPENCE WAS LODGED IN THE IARYNX DURING TEN WEEKS.}

BY

\author{
J. BURDON SANDERSON, M.D., F.R.C.P., \\ ASSISTANT-PHYGICIAN TO THE MIDDLESEX HOSPITAL, AND THE HOSPITAL \\ FOR CONSUMPTION, BROMPTON; \\ AND \\ JOHN WHITAKER HULKE, F.R.C.S., \\ ASSISTANT-SURGEON TO THE MIDDLESEX HOSPITAL, AND TO THE ROYAL \\ LONDON OPHTHALMIC HOSPITAI.
}

Received March 15th-Read June 13th, 1865.

ON Wednesday, November 2nd, the patient, a muscular man, æt. 27, in good health, was talking with some friends in a public-house, having a sixpence in his mouth, when, something in the conversation exciting his laughter, the sixpence disappeared, and he immediately fell to the ground suffocated.

A neighbouring surgeon was called in, who supposed him to be dying, and at once took him to St. Mary's Hospital, where he arrived about three quarters of an hour after the accident, and was placed in bed on his back. He states that his throat was examined, but that nothing could be detected. In a short time his breathing was easier, and he became tranquil. He remained in the hospital till one o'clock the next day, when he was discharged at his own request. He 
affirms that at this time he breathed as well as he had ever done in his life, and could walk fast or go up stairs without any difficulty, but was unable to speak above a whisper. For about a fortnight after the accident he attended at the hospital as an out-patient, complaining of sore throat and pain or difficulty in swallowing liquids, of which symptom he was relieved by treatment. During the succeeding ten weeks his voice remained as before. He lost flesh and strength, but in other respects was in fair health, and never experienced any difficulty of breathing, either on exertion or otherwise.

On the 5th of January his breathing became embarrassed somewhat suddenly, and at 12 o'clock he was brought to see Dr. Sanderson. It appearing, from his statement and from the character of the dyspncea from which he was suffering, that the sixpence was still in his throat, he was directed to come to the Middlesex Hospital for laryngoscopic examination. On returning home he was suddenly seized in going up to his bedroom with a feeling of suffocation and a fear of approaching dissolution as urgent as he had experienced immediately after the accident. He states that he rushed down stairs in agony, and in doing so tripped. Thereupon the dyspnœa suddenly ceased, and he was again able to breathe as freely as ever.

Next day, at 2.30 p.m., he presented himself at the hospital, when the breathing appeared to be only slightly embarrassed. The sixpence was seen without difficulty on the first introduction of the laryngeal mirror. It was horizontally placed in the glottis, below the false vocal cords, which covered a portion of its circumference at each side, leaving exposed a triangular metallic surface, the base of which was formed by the free edge of the coin, while the apex was overhung by the epiglottis. Between the free edge and the arytenoid cartilages was a transversely oblong breathing space, apparently not wider than a tenth of an inch from front to back, and bounded laterally by the posterior extremities of the false vocal cords and the aryteno-epiglottidean folds. The entire visible laryngeal mucous membrane was red and puffy. His breathing was slow (thirteen re- 
spirations per minute), and on listening to his larynx it was found that the two respiratory acts were of nearly equal duration, expiration being slightly longer than inspiration. On percussion it was found that the chest was everywhere resonant, but that the pulmonary margin scarcely extended posteriorly below the level of the ninth dorsal spine in tranquil breathing. On auscultation a feeble inspiratory and expiratory sound of a somewhat tubular character was heard all over the chest, but the natural vesicular murmur could not be distinguished.

It was at once determined to attempt the extraction of the coin with the aid of the laryngoscope, through the upper opening of the larynx ; and inasmuch as its horizontal position rendered it impossible to seize it with forceps, bent loops of wire were prepared for the purpose of jerking it out. As a preliminary tentative measure, the patient was held with his head downwards, smartly slapped on the back of his neck, and directed to cough, which he was unable to do from inability to fill his chest. These measures effected a slight apparent alteration in the position of the coin, but were unsuccessful, and, the mucous membrane having become much more red and turgid, resembling crimson plush, it was resolved to have recourse to laryngo-tracheotomy.

After a delay of four hours, in order to gain the consent of the patient's wife, he was put under chloroform, and a cut one inch and a half long was made in the middle line from the thyroid cartilage downwards. The crico-thyroid membrane, the cricoid cartilage, and two or three upper trachial rings, having been divided, the wound was held apart above and below with two pairs of Trousseau's dilators, while search was made for the coin with a forceps introduced from below. It could be felt, but not seized. An attempt to pass one blade of the forceps in the angle of the thyroid cartilage over the anterior edge of the coin was unsuccessful, though the instrument easily slipped through the glottis behind the coin, and could be felt with the forefinger of the other hand in the fauces. In this attempt the coin was displaced upwards within the reach of the finger, by which it was drawn 
forwards over the epiglottis on to the root of the tongue. At this moment the patient made a sudden gulp, the coin slipped away, and the patient, who had become conscious, made signs that he had swallowed it. Immediately after, he breathed freely through the glottis, the wound remaining open, and on auscultation over the front of the chest air was heard to enter freely. He was at once placed in bed, in a warm, moist atmosphere. The wound was covered with a sheet of cotton wool.

It is unnecessary to give a detailed report from this time. On the following morning he passed the coin per anum; his breathing was easy and noiseless, sixteen respirations per minute, and his pulse was 84 .

On the fourth day his respirations were thirteen, and his pulse 82 per minute.

On the eleventh day his chest was resonant as low as the twelfth dorsal spine, and the vesicular murmur, still singularly weak, could be everywhere heard; his respirations had risen to eighteen, and his pulse had fallen to 64 beats per minute.

For about a week after the operation a little air bubbled through the wound on coughing. Laryngoscopic examinations from time to time revealed a small group of granulations just above the base of the right arytenoid cartilage, near the attachment of the false cord, and diminished puffiness and redness of the laryngeal mucous membrane.

On the 18th of January, when he was made an out-patient, the wound had nearly cicatrized.

By the 20th of February the patient's wound had regained its natural character, but he himself stated that it was not so powerful as it had been before the accident. On examining the larynx it was found that its mucous membrane and that of the epiglottis were still unnaturally red and turgid. The pulmonary signs had undergone no change since he left the hospital. The breathing was still remarkably slow (not more than thirteen respirations per minute), and in many parts of the chest the respiratory murmur was so feeble that it could not be distinguished. 